\title{
Processos de subjetivação no contexto da monocultura de cana-de-açúcar
}

Process of subjectivation in the context of sugar cane monoculture

Procesos de subjetivación en el contexto del monocultivo de la caña de azúcar

\author{
Simone Maria Hüning* \\ Rondineli Bezerra Mariano ** \\ Aline Kelly da Silva ${ }^{* * *}$ \\ Paulo dos Santos Nascimento ${ }^{* * * *}$
}

\begin{abstract}
Resumo
Este artigo resulta de pesquisa realizada em uma comunidade situada geograficamente na propriedade de uma usina sucroalcooleira do Estado de Alagoas, Nordeste do Brasil. O objetivo principal do estudo é discutir os processos de subjetivação de sujeitos que moram e trabalham nesse território. Realizamos entrevistas não estruturadas com moradores, roda de conversa com trabalhadores da usina, visitas à comunidade e registros em diários de campo. Utilizamos o referencial teórico de Michel Foucault para discutir os processos de subjetivação no contexto em estudo. A pesquisa nos permitiu visibilizar diferentes vetores de subjetivação que constituem a vida no cotidiano da comunidade e compõem as formas de existência desses sujeitos. Destacamos, entre esses, a separação entre o que chamam de vida "na usina" e vida "lá fora", as relações com o trabalho, a violência e a religião.

Palavras-chave: Processos de subjetivação. Sistema de moradia. Setor sucroalcooleiro.
\end{abstract}

\begin{abstract}
This article resulted from research conducted in a community geographically located on the property of a sugar and alcohol plant in the state of Alagoas, northeastern of Brazil. The main objective of the study is to discuss the
\end{abstract}

Texto recebido em 12 de maio de 2014 e aprovado para publicação em 18 de dezembro de 2014.

Docente pesquisadora do Instituto de Psicologia da UFAL, coordenadora do Grupo de Pesquisa Processos Culturais, Políticas e Modos de Subjetivação. Endereço: Universidade Federal de Alagoas, Instituto de Psicologia. Avenida Lourival Melo Mota, s/n. ${ }^{\circ}$ - Tabuleiro dos Martins, Maceió-AL, Brasil. CEP: 57072-970. E-mail: simonehuning@yahoo.com.br.

** Mestra em Psicologia pela UFJF, graduado em Psicologia pela UFAL. Endereço: Universidade Federal de Juiz de Fora, Instituto de Ciências Humanas. Rua José Lourenço Kelmer, sn.o - São Pedro, Juiz de Fora-MG, Brasil. CEP: 36036-330. E-mail: rondineligtr@hotmail.com.

${ }^{* * *}$ Mestra em Psicologia pela UFAL, graduada em Psicologia pela UFAL. Endereço: Universidade Federal de Alagoas, Instituto de Psicologia Avenida Lourival Melo Mota, s/n. ${ }^{\circ}$ - Tabuleiro dos Martins, Maceió-AL, Brasil. CEP: 57072-970. E-mail: kelly_ legiao@hotmail.com.

${ }^{* * * *}$ Mestre em Psicologia pela UFAL, graduado em Psicologia pela UFAL. Endereço: Rua Adolfo Gustavo, no 90, bloco E, ap. 104 - Serraria, Maceió-AL, Brasil. CEP: 57046-341. E-mail: prteologo@gmail.com. 
processes of subjectivation of subjects who live and work in this territory. We conducted unstructured interviews with residents, group discussions with plant workers, community visits and records in field diaries. We used the theoretical framework of Michel Foucault to discuss the process of subjectivation in the context under study. The research allowed us to visualize different vectors of subjectivation that constitute everyday life in the community and compose forms of existence of these subjects. We highlight, among these, the separation between what they call life "at the plant" and life "out there", relations with labor, violence and religion.

Keywords: Process of subjectivation. Housing system. Sugar cane context.

\section{Resumen}

Este artículo resulta de una investigación realizada en una comunidad geográficamente ubicada en la propiedad de una planta sucro-alcoholera en el estado de Alagoas, al nordeste de Brasil. El objetivo principal del estudio es discutir los procesos de subjetivación de las personas que viven y trabajan en ese territorio. Realizamos entrevistas no estructuradas con los residentes, ruedas de conversaciones con trabajadores de la planta, visitas a la comunidad y registros en diarios de campo. Utilizamos el marco teórico de Michel Foucault para discutir los procesos de subjetivación en el contexto estudiado. El estudio nos permitió visualizar diferentes vectores de subjetivación que constituyen la vida cotidiana en la comunidad y que componen las formas de existencia de estos sujetos. Destacamos, entre ellas, la separación entre lo que llaman la vida "en la planta" y la vida "allá afuera", las relaciones con el trabajo, la violencia y la religión.

Palabras clave: Procesos de subjetivación. Sistema de alojamiento. Sector sucro-alcoholero.

\section{Introdução}

ste trabalho resulta de uma pesquisa realizada em uma comunidade situada geograficamente na propriedade de uma usina sucroalcooleira, localizada em um dos municípios da Região Metropolitana de Maceió, ${ }^{1}$ composta pelas famílias dos trabalhadores em regime efetivo da respectiva usina - configuração definida como "sistema de moradia" (Albuquerque, 2009). O objetivo principal do estudo foi discutir os processos de subjetivação de sujeitos que vivem e trabalham nesse território, aspecto abordado neste artigo. Destacamos que o contexto social e cultural do Estado de Alagoas, onde essa comunidade se insere, é fortemente marcado pela monocultura da cana-de-açúcar, e assim como outros

\footnotetext{
1 A pesquisa, aprovada pelo Comitê de Ética em Pesquisa conforme processo n. ${ }^{\circ}$ 005790/2011-21, foi realizada entre os anos de 2010 e 2012, com financiamento do Edital Universal CNPq.
} 
autores, compreendemos que a economia canavieira tem produzido efeitos locais que ultrapassam a dimensão econômica (Albuquerque, 2009; Diegues Júnior, 2002), especialmente se considerarmos os modos de subjetivação engendrados pelas relaçóes construídas em torno da cultura e das usinas sucroalcooleiras.

Apesar disso, e a despeito da amplitude desse setor produtivo no Brasil, são poucos os incentivos para estudos da área das Ciências Humanas, Sociais e da Saúde relacionados a ele (Albuquerque, 2009). A situação da Psicologia, e em específico da Psicologia Social, é correlata, e o setor sucroalcooleiro ainda permanece pouco privilegiado como tema de estudos entre aqueles que estão inseridos nesse campo do saber no Estado de Alagoas e no Brasil. Grande parte dos estudos das Ciências Humanas e Sociais publicados foi produzida com base em dados obtidos no contexto da agroindústria canavieira do Estado de São Paulo e é ligada principalmente a uma tradição crítica de denúncia das más condições de trabalho e saúde nesses contextos (Nascimento \& Hüning, 2012).

Assim, buscando contribuir com a discussão dessa problemática e atentando para a situação específica de sujeitos que vivem em uma comunidade do sistema de moradia, o interesse da pesquisa está para além do âmbito das relações econômicas e de trabalho, e, com base na interface da Psicologia Social com o referencial foucaultiano, discutimos a produção de subjetividades buscando abordar diferentes vetores de subjetivação que constituem a vida no cotidiano da comunidade e compõem as formas de existência desses sujeitos.

\section{Monocultura da cana-de-açúcar e processos de subjetivação}

Para além de afetar apenas o setor econômico, a hegemonia da cultura canavieira reflete-se em questóes sociais e políticas do Estado de Alagoas, podendo-se afirmar, conforme Lira (2007, p. 2), que "a história de Alagoas tem como núcleo a história da agroindústria do açúcar”. De acordo com Plancherel, Albuquerque e Melo (2007), apesar de decadente no Nordeste brasileiro, a atividade açucareira ainda é a principal base econômico-social do Estado de Alagoas, a partir da qual se desenvolvem formas de socialização e de reestruturação do trabalho agroindustrial, que geram uma "desigualdade social cuja modernização assume claras especificidades e assimetrias em suas relações sociais e em suas conformações políticas" (Plancherel, Albuquerque \& Melo, 2007, p. 121). A relação entre o desenvolvimento da monocultura do açúcar e a desigualdade social no Estado é também pontuada por Diegues Junior (2002) e Albuquerque (2009). Esses autores destacam a influência do exclusivismo açucareiro nas configurações sociais, políticas e culturais da sociedade alagoana, de forma direta ou indireta, para além do caráter econômico, embora acentuando o empobrecimento das populações. 
Ao lado do que é definido por Diegues Júnior (2002) como as três características essenciais do desenvolvimento do sistema econômico sucroalcooleiro (o processo latifundiário, o exclusivismo de produção e o regime de colonato como substituto ao trabalho escravo), o autor situa a importância da criação da condição de morador (dos banguês, dos engenhos e finalmente das usinas) para o desenvolvimento da hegemonia da cultura canavieira. Tal sistema desenvolveuse conforme, devido à grande demanda de mão de obra nas propriedades de produção de cana e nos engenhos, os proprietários inicialmente ofereciam aos trabalhadores uma porção de terra para a agricultura de subsistência e um espaço para a construção de choupanas, descritas como bastante precárias, em troca de alguns dias de trabalho em suas plantações e engenhos (Sant'ana, 2011). Posteriormente, além da terra para plantar, os proprietários também começaram a dar uma casa já pronta e certa proteção social (Albuquerque, 2009). Esse "acordo" realizado entre proprietário e trabalhador está muito além de uma simples troca de favores. Havia uma sujeição dos trabalhadores aos proprietários, descrito por Albuquerque (2009) como certo tipo de enlace social. Os trabalhadores acatavam determinadas regras e mantinham fidelidade e respeito ao patrão que, em troca, emprestava sua força, reputação e segurança aos moradores.

A economia baseada na monocultura da cana-de-açúcar continua hegemônica em Alagoas. Lira (2007), com base em dados do Censo Agropecuário 2006, produzido pelo Instituto Brasileiro de Geografia e Estatística (IBGE), afirma que a cana ocupa atualmente $69,3 \%$ da área cultivada nesse Estado, predominantemente na Zona da Mata e nos Tabuleiros Costeiros, onde está alocada a comunidade na qual desenvolvemos a pesquisa. De todos os trabalhadores ligados à atividade industrial no Estado, 81\% estão vinculados, de alguma maneira, àquele setor (Lira, 2007). Nesse cenário, consideramos relevante analisar como essa hegemonia inscreve-se no modo como os sujeitos envolvidos diretamente nesse universo se produzem.

Compreendemos, a partir de Foucault, que os processos de subjetivação são engendrados por uma rede de relações envolvendo práticas, objetos e discursos, relaçôes de poder e saber, produtoras de seres em contínua transformação. Subjetivação é entendida aqui como o "processo pelo qual se obtém a constituição de um sujeito, mais precisamente de uma subjetividade, que evidentemente não passa de uma das possibilidades dadas de organização de uma consciência de si" (Foucault, 2006, p. 262). Subjetividade refere-se a modos transitórios e fluidos de experienciar a si mesmo e a seus modos de agir (Candiotto, 2008). Buscamos aqui dar visibilidade à singularidade dos processos de subjetivação nos contextos da cultura da cana. 


\section{Territórios, pessoas e estratégias de encontro na pesquisa}

A comunidade onde desenvolvemos a pesquisa situa-se em um dos municípios da Região Metropolitana de Maceió e é composta por trabalhadores efetivos ${ }^{2}$ de uma usina sucroalcooleira e seus familiares. Remonta à implantação da atividade canavieira na região, no século XIX (primeiro como banguê e posteriormente como engenho). Atualmente é composta por cerca de 1.500 pessoas que residem na propriedade da usina, segundo informação obtida dos próprios moradores. Dispóe de escola pública de ensino fundamental e médio, posto de saúde, centro recreativo, sindicato dos trabalhadores ligados à usina, auditório público destinado a atividades culturais e entidades religiosas. Os moradores pagam aluguel pelas casas que ocupam na propriedade da usina, e quando os trabalhadores se desvinculam da empresa, por demissão ou aposentadoria, devem deixar a comunidade.

Realizamos entrevistas não estruturadas com pessoas que moram na comunidade, sendo a primeira delas com uma pessoa que conhecia um membro da equipe de pesquisa, e as demais seguiram indicações dos próprios moradores. Buscamos manter um caráter de diálogo, abordando questões como as histórias de vida e da comunidade, os modos de relações e práticas cotidianas desses sujeitos. Fomos autorizados a gravar quatro entrevistas, com cinco moradores (trabalhadores da usina, esposas e filhos dos trabalhadores) que receberam nomes fictícios neste trabalho. Além desses, outros moradores foram contatados e, embora tenham concordado em conversar sobre as questôes propostas, não autorizaram gravação. As entrevistas autorizadas e gravadas foram transcritas na íntegra e entregues aos participantes, caso esses quisessem fazer alguma observação, porém não tivemos nenhum retorno a respeito. Os demais contatos constituíram notas de campo que nos auxiliaram a compreender e problematizar as dinâmicas da comunidade.

Também realizamos uma roda de conversa da qual participaram cinco trabalhadores da usina/moradores da comunidade, que não participaram da etapa anterior e foram indicados por um dos trabalhadores previamente entrevistado. Foi autorizada a gravação desse encontro, porém grande parte foi perdida por problemas técnicos, restando-nos as notas de campo sobre esse momento.

Durante a realização da pesquisa também fizemos visitas à comunidade, por vezes acompanhados por moradores, buscando conhecer sua configuração e os modos de circulação nesse território. Essa estratégia nos colocou em contato, entre outros aspectos, com a prática de segurança adotada na propriedade, desde

\footnotetext{
A categoria "trabalhadores efetivos" serve como diferenciadora daqueles não efetivos, ou safristas. Em oposição aos efetivos, que têm vínculos empregatícios perenes com as usinas, os safristas são trabalhadores sazonais agregados à dinâmica das usinas apenas nas épocas de colheita e moenda da cana, que duram seis meses do ano. Entre estes, os cortadores de cana são o melhor exemplo.
} 
o ingresso, através de uma guarita vigiada, como pela restrição dos espaços de circulação acessíveis a visitantes e moradores, no interior do lugar.

Em nossas análises atentamos para os modos de os sujeitos perceberem a si bem como sua experiência no mundo; as formas como se relacionam consigo, entre si, com o lugar e com o contexto histórico-cultural que os cerca, considerando principalmente os discursos instituídos que transversalizam a experiência de vida nessa comunidade; vetores de subjetivação que se destacam; o cotidiano, modos e histórias de vida nesse lugar.

\section{A produção da vida no contexto da monocultura da cana-de-açúcar}

O senhor pensa em sair daqui? (Pesquisadora)

Eu penso demais. Apesar de que a gente que é um ser humano, a gente se acostuma até com o que não presta, entendeu? Eu acho aqui um lugar bom de morar [...] Eu sempre pensei muito em sair daqui pra ir lá pra fora. Mas eu vejo assim a violência que eu fico me segurando de tentar comprar uma casa lá fora por causa disso. Fico pensando em meus filhos, né, jovens, chegar lá fora. Como é que eles vão se comportar no meio daquelas pessoas estranhas? Tudo bem. Daqui pro Bairro [nome do bairro próximo] é bem ali. Mas tem muita diferença daqui pra ali. [...] Muita diferença! Uma criança criada aqui, ele chega lá... vamos dizer assim, meu filho tem 13 anos. Mas se ele chegar ali um menino de 10 anos enrola ele ali. Porque, vamos dizer assim, a cultura ali já é mais avançada do que aqui, né? E isso é uma coisa que eu fiquei assim na minha mente, porque a minha filha mesmo cobra muito de mim pra estudar, fazer o curso, essas coisas, e aqui é tudo difícil pra eles. O ônibus só vai até o Bairro [nome do bairro]. Você pode querer fazer um curso, mas você tem que ter dinheiro todo dia pra passagem. Se o curso acabar $22 \mathrm{~h} 30 \mathrm{~min}$, é complicado pra chegar aqui. É difícil você chegar aqui. O ônibus sai do colégio do Bairro [nome do bairro] $22 \mathrm{~h}$. Não dá tempo de chegar. É tudo complicado. Pra você se profissionalizar aqui dependendo de estudar lá fora, é muito complicado, porque não tem oportunidade. Vou dizer assim, até pelos jovens. Se o pai tiver condições pra pagar o colégio, tem que pagar um curso pra eles lá fora, porque eu acho também que não era nada demais a empresa ter um convênio com algum colégio pra educar os próprios filhos dos funcionários, pra quando for no futuro estarem até trabalhando pra eles mesmo [para os empresários], não é verdade? Mas isso eles não fazem. (João)

João mora e trabalha na usina há 26 anos. Não informou a idade, e estimamos que tem aproximadamente 60 anos. Começou a falar sobre a vida e o trabalho na usina sem que fizéssemos qualquer pergunta. Ele já esperava por nossa visita, que havia sido informada pela esposa. Apenas nos apresentamos, e ele iniciou sua narrativa. Nós o interrompemos para solicitar as autorizações formais para a participação na pesquisa e iniciarmos a gravação. Em seguida, o trabalhador retomou sua narrativa. Bastante emocionado, João assumiu uma postura de enfrentamento e denúncia das situações de humilhação e desrespeito vivenciadas principalmente no cotidiano de trabalho na usina. Atualmente, João sofre com 
problemas de saúde decorrentes de sua atividade profissional e não se sente amparado pela empresa. Seu relato é impactante. Para esse morador e trabalhador da usina, são evidentes as marcas desse contexto cultural na produção de suas formas de compreender e si e ao mundo. Ao falar de seus filhos e suas diferenças em relação às crianças criadas "lá fora", ao falar de suas possibilidades de trabalho e de como "aprendeu" a lidar com elas, ao falar de seus projetos, perspectivas, escolhas, possibilidades, de sua saúde e de sua família, é à usina que se refere como constituinte desses processos:

Aqui há tranquilidade pra gente viver, né? Nesse lado é uma maravilha aqui, pra você viver sossegado. Se for possível, a gente bota uma bicicleta do lado de fora na rua e ela fica aí, fica toda molhada do orvalho da noite, mas ninguém bole, né? A minha mesmo dorme aí, embora que eu não sei se porque é velha ou não, mas dorme na calçada, sem cadeado sem nada [risos de todos]. Tem umas vantagem... Mas, assim, nós somos cidadãos e nós como cidadãos nós temos que ter nossa cidadania. Eu não tenho um carro. Faz tanto tempo que eu trabalho e não tenho um carro, né? Isso é sinal de cidadania, não é verdade? Ter uma casa... Tantos anos que trabalha em uma empresa, é pra ter isso, pelo menos uma moto, poder levar sua família ao shopping, né, e assim, passear ali no centro no dia de folga. Mas às vezes você trabalha muito e ganha pouco e não dá pra fazer aquilo que o seu coração deseja fazer. (João)

Condições de trabalho, sonhos de consumo que se entrelaçam com uma noção de cidadania, sentimento de segurança, medo da violência, territórios delimitados entre uma vida "lá fora" e uma vida "na usina" (expressão usada pelos moradores para se referir, não apenas à empresa, mas ao lugar onde moram) compõem as complexas, e por vezes, paradoxais e controversas experiências dos sujeitos com quem conversamos. Entre diferentes elementos, entendemos que o trabalho na usina (que é a condição inicial para morar na comunidade) pode ser pontuado como um dos principais vetores de subjetivação que constitui tanto trabalhadores como seus familiares nesse território. Em relação a esse, experiências que se constituem por constantes referências a situações de violência vividas pelos trabalhadores, mas que nem sempre foram assim nomeadas. O território vigiado e protegido da usina resguarda a violência do "mundo lá fora", ao mesmo tempo em que produz violências nada sutis, porém, de certo modo, naturalizadas nas relações de trabalho no contexto da monocultura da cana-de-açúcar. Seguindo seu relato, João fala sobre dificuldades vividas:

Dos momentos difíceis da minha vida, esse momento de depressão foi o pior. No meu ponto de vista, foi tudo a ver com o trabalho, tudo a ver com o trabalho. [. . .] Você vai, vai, vai, e uma hora você não tem tanto nervo pra aguentar tanta pressão, não é verdade? [...] Quando eu comecei a trabalhar aí, eu era forte, não sentia nada disso, e hoje eu sou 
um cara que eu não aguento [verbo incompreensível] mais de meia hora, não suporto, não posso perder sono, se uma pessoa fizer muita raiva a mim, eu fico inquieto, sem dormir, tá entendendo? Eu estou dessa maneira assim, e isso daí tudo foi motivo do emprego da usina, né, do serviço de lá. [. . .] E assim, eu fico um pouco triste. Eu queria estar lá, junto, trabalhando, apesar de tudo. Como eu falei, a gente se acostuma com o que não presta. Mas, mesmo assim, eu queria estar trabalhando, né? Não queria estar me mantendo por esse INSS, porque isso daí eu acho uma humilhação.

Ao mesmo tempo em que relata um sentimento de humilhação por não poder se sentir mais produtivo, João recorda outras situações em que, na execução de seu trabalho, foi tratado com desrespeito e humilhado por parte dos encarregados. Carlos, 47 anos, trabalhador da usina, que nasceu e cresceu na comunidade, ausentando-se apenas por um período de 6 anos, compartilha memórias de desrespeito durante a rotina de trabalho, afirmando explicitamente a intenção de seu superior em humilhá-lo:

Ele só me chamava de papel higiênico. "Você é um papel higiênico, você não serve pra empresa, uma pessoa como essa aí era pra ser botado pra fora.” [. . . Nisso ele me chamou assim "Carlos, vem cá... Carlos não, papel higiênico. Oh, papel higiênico, vem cá! Tira essa presilha aqui pra eu ver uma coisa”. Aí eu fui tremendo, ia tremendo, peguei o alicate pra tirar essa presilha, eu quase não equilibrava tremendo. Aí ele "Oh, pessoal, pare tudinho aí. Venha olhar uma pessoa que não serve”. Aí chamou o pessoal tudinho, um montão de gente e eu no meio pra tirar aquela presilha. Sabe o que é tremer? Eu não falava, só descia lágrimas dos meus olhos e aquela gosma na minha boca.

Frequentes relatos feitos durante a pesquisa nos sinalizaram uma institucionalização de práticas de violência vividas por esses trabalhadores "Trabalhei com pessoas lá que queriam fazer de você um lixo humano, né" (João).

A precariedade da situação de trabalho ultrapassa essas experiências de humilhação. Foi recorrente nas entrevistas a menção ao desrespeito a aspectos formais da legislação trabalhista. Todos os trabalhadores com quem conversamos nos informaram o atraso de aproximadamente 15 anos no depósito do Fundo de Garantia por Tempo de Serviço (FGTS) e o frequente atraso no pagamento de salários. Quando esse quadro foi mencionado na situação do grupo de trabalhadores, interrogamos sobre a presença e a atuação do sindicato dos trabalhadores, já que um deles fazia parte dessa entidade. Nossa pergunta foi respondida com outra pergunta, formulada por um dos participantes: "Quem manda nesse Estado? São todos os mesmos, as mesmas famílias". Marcaram assim seu sentimento de impotência de ação e enfrentamento legal 
das situações vivenciadas no universo do trabalho, diante da concentração de poder dos usineiros no Estado, nos campos econômico, jurídico e político. Esses trabalhadores reconhecem o descumprimento de direitos, mas veem pouca possibilidade de que estes sejam respeitados, situação que não passa por um desconhecimento desses direitos, mas por uma descrença de que eles possam valer nesse contexto. $\mathrm{O}$ sentimento de humilhação e pouca valorização do trabalhador é compartilhado pelos familiares: "A profissão que as pessoas têm... eu acho que elas deveriam receber mais por isso. Não acho um salário digno, não. E as pessoas não procuram outros lugares com medo" (Patrícia, 17 anos, nasceu e sempre morou na comunidade).

Paradoxalmente, ainda que o trabalho na usina seja percebido como fonte de sofrimento, adoecimento e humilhação, é também pelo trabalho que esses mesmos trabalhadores afirmam constituir-se e encontrar reconhecimento. Os trabalhadores alegam que por meio do trabalho se tornaram alguém, distanciandose de situações que são consideradas mais degradantes nesse contexto, como o corte de cana ou o desemprego. Assim, produz-se entre os próprios trabalhadores uma hierarquização de postos de trabalho que corresponde à qualificação e especialização destes para a execução de determinadas atividades em diferentes setores da usina (os mecânicos, por exemplo, falam com orgulho de seu saber especializado e de sua relevância para o seu funcionamento), que, se por um lado, converte-se em um sentimento de realização, por outro, opera como mais um elemento de sujeição ao modo de vida institucionalizado nesse setor produtivo. Assim, os mesmos trabalhadores que nos relataram as mais diversas queixas e problemas relacionados ao trabalho na usina, falam da gratidão por ter aprendido um ofício e ter conquistado o seu lugar de destaque no quadro de funcionários da empresa:

Eu não vou falar também só do lado negativo. Tive oportunidade de aprender a ser um profissional. Me profissionalizei lá, né? Aprendi umas profissōes lá: soldador, lubrificador, tornilheiro... Eu agradeço também essa oportunidade que eu tive de me profissionalizar lá. Eu sem fazer curso, mas aprendi isso tudo lá. (João)

Ou, como expressa Carlos:

Hoje em dia, nessa usina aqui, nessa usina não, nessa empresa, hoje em dia, eu fiz meu nome; hoje em dia, eu sou um cara conhecido... Hoje em dia, eu sou um cara, eu sou um tipo de cara quase completo. Não sou completo porque eu não tenho estudo.

Os trabalhadores afirmam sua importância por sua contribuição para a empresa. $\mathrm{Na}$ roda de conversa com o grupo de trabalhadores, eles afirmaram ter 
conseguido reconhecimento e realização pessoal pelo trabalho e comentam que a usina ensina mais que uma faculdade. No entanto, em nosso contato inicial com esse grupo e antes de começarmos a gravação, os trabalhadores nos alertaram que não falariam de tudo, não falariam sobre coisas que pudessem prejudicá-los, e supomos, pelos silêncios e ritmos da conversa, que muito do que não foi dito diz respeito à sua rotina de trabalho. Dizem que se as pessoas souberem aproveitar a oportunidade, todos podem crescer, comprar seu carro. "Eu não comprei porque gastei tudo com bebida", finaliza um dos trabalhadores participantes do grupo. Ninguém, no entanto, relaciona o consumo excessivo de álcool, situação mencionada como comum nesse contexto, com a própria situação de vida e trabalho na usina, embora em outros momentos esse tenha sido pontuado como a única atividade de lazer existente na comunidade.

O trabalho, fonte de reconhecimento e sofrimento, produz sujeitos marcados pela privação, amedrontados pelo poder dos proprietários e pela perda do único recurso de subsistência e moradia. Situação, aliás, reinstaurada constantemente pelos rumores de crises financeiras do setor alcooleiro e da própria usina, insinuando até mesmo seu fechamento, que frequentemente circulam entre os trabalhadores, afirmando que seus postos de trabalho estão em perigo. No dia em que retornamos à comunidade para entregar aos participantes as transcrições das entrevistas concedidas, um dos trabalhadores nos informou que, mais uma vez, os salários estavam atrasados, porque a usina enfrentava dificuldades econômicas. Concluiu dizendo que pior seria se ela fechasse, então tinha de ser paciente...

Mesmo diante das graves denúncias feitas sobre o desrespeito e humilhação no cotidiano de trabalho, nos impressiona que estas em nenhum momento foram associadas à palavra violência, algo atribuído sempre ao mundo exterior. Para nós, é evidente que tais situaçôes podem ser qualificadas como formas de violência contra o trabalhador, heranças das relações informais de trabalho típicas do setor canavieiro das quais nos fala Albuquerque (2009). Ainda que formulem esses testemunhos de violência, nas narrativas sobre a vida no lugar, essa é sempre situada como um problema relativo ao exterior. A comunidade, como já discutimos, é definida pela tranquilidade e ausência de violência, o que faz com que eles optem por permanecer no local mesmo este sendo precário e deficitário em diversos aspectos: "Lá fora é tão difícil, a gente vê tanta coisa..." (Joana, 47 anos, mora na comunidade desde que nasceu).

Ouvimos um único relato nomeado como uma situação de violência vivida dentro da usina, correspondente a uma briga ocorrida na década de 1990 e atribuída a pessoas de fora da comunidade: 
E só teve aqui uma vez que, um dia de domingo, teve uma violência grande aqui. Isso foi à base de 1991 pra 1992, por aí. Chegou uma pessoa aí querendo bagunçar [...], aí foram chamar a vigilância, e chegou a turma pedindo pra acalmar, esperando acalmar, e começou a trocar bala e mataram quatro pessoas. Os cara de fora aí... Mataram quatro pessoas. (João)

De forma unânime e recorrente, a segurança e a tranquilidade foram associadas à permanência no território da usina e, por outro lado, a violência nos bairros situados no entorno, e no Estado em geral, fator de afastamento desses locais e de conformação à vida na usina. Maria, que tem 41 anos, nasceu e viveu toda sua vida na comunidade reafirma esse discurso:

Assim, às vezes, me bate um medo, assim né, de morar fora por causa da violência. Aqui, por mais que seja assim, pra recursos assim, sobre saúde mesmo, assim, é difícil, mas aqui é um lugar, assim, de paz, é um lugar bom de se morar, basicamente de conviver tudo tranquilo e [incompreensível] de ir lá pra fora por causa dessas violências mesmo que a gente vê lá fora. Mas pra viver mesmo assim aqui, sobre recursos mesmo daqui... É difícil precisar de recursos daqui...

O ambiente urbano é percebido e classificado como ameaçador principalmente por conta de assaltos, homicídios e tráfico de drogas. A cidade é vista como sinônimo de violência enquanto a comunidade significa tranquilidade e proteção contra o mundo "lá de fora", com o qual o contato cotidiano dessas pessoas se dá principalmente pela programação midiática local, na qual questôes como insegurança, violência e medo são cada vez mais divulgadas e comentadas. Maceió desponta nos índices estatísticos como a capital mais violenta do País. E a violência "lá de fora", ao lado das condições precárias de trabalho, desponta como mais um importante vetor de subjetivação no espaço privado da comunidade, que passa a compor os cálculos do tipo de vida a ser vivida, juntamente com as parcas possibilidades de escolhas dadas a essas pessoas.

Nesse processo, as diferentes formas de violência produzidas na própria comunidade, principalmente nas situações de trabalho, são mais facilmente toleradas e percebidas, talvez, como elementos naturais, constituintes da vida desses sujeitos: "Apesar de que a gente que é um ser humano, a gente se acostuma até com o que não presta" (João).

Os limites geográficos da comunidade criam uma cisão da vida "na usina" com a vida exterior. As saídas relacionam-se a situações de necessidade e, esporadicamente, lazer e estudo. Na usina, a regulação dos modos de vida extrapola 
o ambiente de trabalho e perpassa a vida cotidiana. Essa regulação envolve tanto mecanismos disciplinares que buscam regrar e instituir os comportamentos adequados para a vida na comunidade (presença de vigilantes e seguranças, normas e mecanismos de punição) bem como a oferta das possibilidades dadas aos moradores desse espaço (lazer, relações entre as pessoas, uso e circulação dos/ nos espaços, acesso a serviços). "Toda a vida, aqui foi uma coisa meio rígida, tá entendendo? Aqui chegou um tempo que eu acho que tinha mais de 150 vigilantes aqui, tá entendendo?” (João).

Há, no entanto, nuanças nesse processo de controle e regulação, relacionado principalmente, segundo os moradores, à mudança dos proprietários da usina. A relação anteriormente mais próxima, com a família de usineiros, implicava uma série de trocas e possibilidades que se extinguiram com o fato de hoje os moradores sequer saberem quem são seus "patróes". Todos os participantes referiram-se à diferença entre esses dois momentos, a partir das atividades de cunho social, cultural e de lazer anteriormente proporcionadas na usina:

\footnotetext{
Tinha discoteca, baile, tinha piscina aqui, que sábado, domingo e feriado era aberta... E tinha também os times de futebol, e cada domingo um time fazia um baile, né. [...] Não era como hoje. Hoje acabaram isso. Tinha muitos bares por aí, e hoje acabaram. Tinha mais de 15 bares por aí fazendo barulho. E a gente aqui tinha festa, e nessa brincadeira o povo brigava aí, arengava, e tal, e quando acontecia alguma coisa aqui mesmo era por causa de negócio de cachaça, né. Tinha vez que os vigias faziam um abraçar o outro: "Abrace seu parceiro. Você não tem vergonha não? Você é daqui mesmo e querendo brigar com o outro?”. Aí se abraçavam, tal, e ficava por isso mesmo. (João)
}

De acordo com os participantes de nossa roda de conversa, que também se referem à existência de festas, folguedos e outras expressões da cultura local em tempos anteriores, a proibição dos bares na usina ocorreu devido aos inúmeros desentendimentos suscitados em ocasiōes de embriaguez. Nas recordações de Joana, as festas e bailes, organizados no passado pela própria usina, correspondem aos momentos mais felizes já vividos na comunidade: "Tinha umas festa aqui que era das melhores festas, final de ano... Era o lazer de quem morava aqui. A gente ficava muito alegre porque, final de ano, a gente ia tudo pra festa. Tinha parque, roda-gigante, barco, essas coisas... e tudo isso acabou".

Os moradores relatam, com saudosismo, que, na época em que a família proprietária da usina morava na fazenda, esta estabelecia uma relação mais próxima com os moradores e trabalhadores da comunidade: "Ah, eles paravam, eles falavam com todo mundo, né...”. Essa relação também era perpassada por formas de assistência. Um dos trabalhadores, na roda de conversa, conta: "D. Fulana nos chamava de filhos. Quando precisávamos de algo, nos dava." 
Assim, se tivesse um doente, e realmente fosse uma doença que pudesse gastar com medicação ela ajudava. Os outros donos, assim, os mais velhos, né, eram melhores. A gente poderia chegar até a eles. Agora, estes aqui, a gente não sabe nem quem são. A gente nem sabe quem é o dono da usina! Aí não dá pra chegar. (Joana)

A relação com os antigos donos era mais marcada pelo enlace social de que fala Albuquerque (2009) do que na atualidade. Em troca de assujeitamento às suas exigências e respeito, os senhores da fazenda prestavam alguns favores, como auxílio na doença ou dinheiro para comprar um botijão de gás. Aos atuais donos eles não têm acesso, seja para pedir qualquer forma de ajuda ou mesmo para saber para quem trabalham. No que concerne às formas de relação social, os moradores consideram que, no passado, a vida era melhor pela razão de que se podia pedir auxílio aos donos da usina e por haver mais atividades de lazer e recreação. Os moradores sempre se referem a esse período como um bom momento na história da comunidade. A extinção da oferta de atividades de lazer pela usina, combinada às precárias condições financeiras e ao distanciamento da cidade, praticamente limita a vida dessas pessoas ao trabalho, seja na usina (para os homens), seja na casa (para as mulheres).

A alternativa de atividade ao trabalho mais mencionada foi a prática religiosa. Há, nessa pequena comunidade, várias igrejas de diferentes religiōes, o que nos fala da presença da religiāo como um importante vetor de subjetivação nesse espaço. Maria diz que seu marido "gosta daqui por causa da igreja... Ele não liga em outras coisas, só pra igreja mesmo". Ela própria justifica a sua não participação em outras atividades da comunidade, que são poucas, por sua formação religiosa que já vem de seus pais. João também enfatiza que, quando não está trabalhando, não se envolve com outra coisa que não a religião. Joana relata que, fora o trabalho de casa, somente resta a igreja. Essa rotina marcada quase que exclusivamente por obrigações (uma vida construída pelo sacrifício, tão presente nas religiōes cristãs) faz-nos concluir que a marca da austeridade é bastante presente nas vidas dessas pessoas. A religião é uma ferramenta poderosa para oferecer a esses sujeitos os meios para que compreendam sua experiência, além de orientar a sua conduta e fazer com que suportem a dureza da vida nessas precárias condições.

\section{Considerações finais}

Considerando que a produção de subjetividades se dá de forma processual, a pesquisa sobre os modos de subjetivação deve sempre acenar para seus limites em acompanhar tal processualidade. As estratégias metodológicas adotadas na 
pesquisa buscaram ampliar as possiblidades desse acompanhamento, porém algumas características dessa comunidade restringiram nosso contato. Uma das principais foi a falta de liberdade para ingresso e circulação bem como a tensão, por parte dos moradores e pesquisadores, sobre quem poderia ouvir sobre o que falávamos, mesmo quando estávamos nas casas das pessoas que aceitaram participar da pesquisa. Assim, de acordo com nossos objetivos, podemos dar visibilidade a algumas formas de experiência e processos de subjetivação com suas contradiçóes e paradoxos buscando analisar criticamente a variada gama de discursos aí produzidos. Para tanto, procuramos priorizar um olhar sobre aquilo que os sujeitos vivenciam cotidianamente, as práticas culturais que se produzem no território em que habitam e trabalham.

Nós nos afastamos, portanto, da produção de um conhecimento representacional sobre a realidade dos sujeitos inseridos na comunidade pesquisada, ou uma verdade que represente objetivamente seus modos de vida, e buscamos, em consonância com o que propõe Foucault (1999), reativar saberes sujeitados, acionar discursos "marginais" e colocá-los em confronto com discursos unitários e homogeneizantes. Definimos, assim, o compromisso da pesquisa não somente com a produção de dados, mas, sobretudo, com a vida (Mairesse \& Fonseca, 2002).

É no contexto da hegemonia da monocultura de açúcar que devemos situar os processos de subjetivação e as relações de poder que se estabelecem na comunidade, e um dos primeiros aspectos que se destaca nas experiências relatadas é a compreensão de uma vida doada ao setor sucroalcooleiro, a partir da qual a existência dos moradores desenrola e se concretiza. Vetores como o trabalho, a violência, a religião, o consumo, a cidadania se entrelaçam na composição dessas vidas que demarcam as fronteiras de sua existência a partir da distinção entre o mundo "da usina" e o mundo "lá fora". Embora, em um primeiro momento, esses dois mundos possam parecer distantes e incomunicáveis, é exatamente seu entrelaçamento que compõe grande parte das experiências dessas pessoas. $\mathrm{Na}$ relação com o medo do mundo lá fora, da violência urbana fora da usina, constrói-se o sentimento de tranquilidade e a segurança em relação ao lugar onde se vive, tornando, muitas vezes, invisíveis, ou pelo menos mais suportáveis, as violências e injustiças aí perpetradas e naturalizadas.

Se tomarmos o relato de João sobre suas condições de trabalho e as transformaçôes ocorridas na usina ao longo dos anos, podemos acompanhar sua relação com as mais recentes configurações do capitalismo neoliberal, calcado na flexibilização das relaçôes de trabalho e na culpabilização individual (Bauman, 2001) por "fracassos" ou "sucessos". No choro de Joana, que embarga sua voz ao 
ser perguntada sobre a infância de trabalho no canavial, no olhar e na indignação do tom de voz de João, ao falar sobre as ocasiōes em que entrou no banheiro para chorar e sobre a impotência sentida diante de uma lesão muscular seguida de depressão, que o impossibilitaram de continuar trabalhando, afetos que tensionam o que talvez suas palavras não consigam expressar. É isso que pode ser registrado a partir de suas histórias: a afetividade como elemento presente na produção de territórios de existência (Bomfim, 2009).

Esses movimentos, formas de violência e opressão engendradas e instituídas pelo sistema cultural, político e econômico de Alagoas, precisam ser visibilizados e denunciados. É a partir disso que podem ser mobilizadas, não apenas pelos próprios sujeitos, mas por setores competentes do Estado, formas de intervenção e apoio que amparem, encorajem e suportem uma mudança nas condiçóes de vida dessas pessoas, cuja posição de fragilidade no campo social é proveniente da própria história de nossa colonização e dos caminhos tomados para o desenvolvimento econômico do Estado, desvinculados do seu desenvolvimento social. Pois, quando nos falam que o mundo da usina é mais seguro do que o "mundo lá fora", o que se denuncia não é apenas uma condição dessa comunidade, mas é também um Estado que se faz ausente para aqueles que ousarem viver suas vidas para além dos domínios da segurança oferecida na propriedade das usinas, sob a proteção e comando dos usineiros. 


\section{Referências}

Albuquerque, C. F. de (2009). Cana, casa e poder. Maceió: Edufal.

Bauman, Z. (2001). Modernidade líquida. Rio de Janeiro: Jorge Zahar.

Bomfim, Z. A. C. (2009). Cidade e afetividade como categorias de mediação na Psicologia social e na Psicologia ambiental. In J. Bernardes \& B. Medrado (Orgs.), Psicologia social e politicas de existência: fronteiras e conflitos (pp. 163173). Maceió: Abrapso.

Candiotto, C. (2008). Subjetividade e verdade no último Foucault. Transformação, 31(1), 87-10.

Diegues Júnior, M. (2002). O banguê das Alagoas: traços da influência do sistema econômico do engenho de açúcar na vida e na cultura regional. Maceió: Edufal.

Foucault, M. (1999). Em defesa da sociedade: curso no Collège de France (19751976). São Paulo: Martins Fontes.

Foucault, M. (2006). O retorno da moral. In M. Foucault, Ética, sexualidade, política. (2a ed.) (Vol. 5, pp. 252-263). Rio de Janeiro: Forense Universitária. (Coleção Ditos e Escritos).

Lira, F. (2007). A formação da riqueza e da pobreza de Alagoas. Maceió: Edufal.

Mairesse, D. \& Fonseca, T. M. G. (2002, julho, dezembro). Dizer, escutar, escrever: redes de tradução impressas na arte de cartografar. Psicologia em Estudo, 7 (2), 111-116.

Nascimento, P. \& Hüning, S. M. (2012). Conhecimento científico, poder e subjetividade no contexto canavieiro do Brasil. Revista Polis e Psique, 2 (2), 23-42.

Plancherel, A. A., Albuquerque, C. F. \& Melo, S. R. G. S. (2007). Trabalho na agroindústria açucareira de Alagoas. Latitude, 1 (2), 119-134.

Sant'ana, M. M. (2011). Contribuição à história do açúcar em Alagoas. (facsímile.) Maceió: Cepal. 